\title{
The evaluation of water's sustainable development
}

\author{
Lingyu Huang \\ School of North China Electric Power University, Baoding 071000, China
}

ABSTRACT: In recent decades, the development of the economy is very fast. However the environment is damaged deeply. More and more people put forward the definition of "sustained development" to solve the problem, which is called sustainability. Because the availability of water is a matter of life and death. We focus on the sustainability of water resource. In order to measure the level of sustainability of a country's water resource. We establish the Supply-and-Demand-Matching Model to measure i.e. define the indexes of Supply Ability (SA), Demand Level (DL) and Matching Degree (MD), which objectively reflect the water ability. The first two indexes (SA and DL) are determined by indicators (17 in total, such as National Rainfall and Agriculture Use ) of two grades, and the third index (MD) is decided by SA and DL. We use two methods in the model, including Principal Component Analytic (PCA) and Analytic Hierarchy Process (AHP).PCA is applied to reduce dimensions of indicators in the second grade, while AHP is employed to give the weights of indicators in the first grade. Finally, 10 typical countries are selected to evaluate by SA, DL and MD. The results show that our model is reasonable.

KEYWORD: sustainability; Supply-and-Demand-Matching Model; Analytic Hierarchy Process (AHP); Principal Component Analytic (PCA)

\section{INTRODUCTION}

With the development of the society, many kinds of resource are consumed, so sustainable development come up. Sustainable development means using finite resource to meet Human needs. It's an ideal situation that we get what we want without undermining the "stability and beauty" of natural biological.

As early as 1987, people said that development should meet the needs of the present without compromising the ability of future generations to meet their own needs. However, the fact is that sustainable development carry out badly. It is necessary for us to measure different countries' sustainability. Now we focus on the water resource, to find a method to estimate the sustainability of water resource.

\section{MAIN FACTORS SELECTION FOR SUSTAINABILITY}

Through the data provided by the Food and Agriculture Organization of the United Nations, we carefully selected the typical indicators used in our model, shown in Table 1,2

Table 1 Supply Indicators of Water

\begin{tabular}{|c|c|c|c|c|}
\hline \multicolumn{5}{|c|}{ Supply Indicators of Water } \\
\hline $\begin{array}{l}\text { Destination } \\
\text { Grade }\end{array}$ & $\begin{array}{l}\text { First } \\
\text { Grade }\end{array}$ & $\begin{array}{l}\text { Second } \\
\text { Grade }\end{array}$ & & $\begin{array}{l}\text { Indicator } \\
\text { Nature }\end{array}$ \\
\hline \multirow{9}{*}{$\begin{array}{l}\text { Supply } \\
\text { Ability }\end{array}$} & National Rainfall(mm/year ) & & $\downarrow$ & \multirow{8}{*}{$\begin{array}{l}\text { positive } \\
\text { indicator }\end{array}$} \\
\hline & \multirow{2}{*}{ Water Ertering the Country $\left(\mathrm{m}^{\wedge} 3 /\right.$ year $)$} & Surface Water & $\rightarrow$ & \\
\hline & & Ground Water & $\rightarrow$ & \\
\hline & \multirow{5}{*}{ Water Withdrawal(m^3/year) } & Renewable Resources & $\uparrow$ & \\
\hline & & Agriculture Water Withdrawal & & \\
\hline & & Industrial Water Withdrawal & $\uparrow$ & \\
\hline & & Life Water Withdrawal & $\uparrow$ & \\
\hline & & Sewage Treatment Capacity( & & \\
\hline & Water Pollution Ratio (\%) & & $\mathrm{r} \rightarrow$ & negative \\
\hline
\end{tabular}


Table 2 Demand Indicators of Water

\begin{tabular}{|c|c|c|c|c|}
\hline \multicolumn{5}{|c|}{ Demand Indicators of Water } \\
\hline Destination Grade & First Grade & Seconc & & \\
\hline \multirow{7}{*}{ Demand Level } & \multirow{3}{*}{ Agriculture } & Agriculture Use(m & $\uparrow$ & \multirow{7}{*}{$\begin{array}{l}\text { positive } \\
\text { indicator }\end{array}$} \\
\hline & & Total Cultivated A & $\uparrow$ & \\
\hline & & Agriculture, value & & \\
\hline & \multirow{3}{*}{ Domestic } & Household use & $\uparrow$ & \\
\hline & & Population Density & $\uparrow$ & \\
\hline & & GDP per capita & $\uparrow \uparrow$ & \\
\hline & Industrial Use & & $\uparrow$ & \\
\hline
\end{tabular}

Explanations for indicators:

Both the supply and demand indicators have two grades. In the supply indicators, it is difficult for the physical indicators (like rainfall) to increase to relieve the water stress. Thus, for its potential value, the Water Withdrawal is divided into four indicators in detail.

According to the literature, agricultural water use accounts for about $75 \%$ of total global consumption. In the demand indicators, we divide the agriculture into three parts for it's widely use, domestic into three parts for its importance.

We collect 2012's data of ten countries from different continents, including Congo, Libya, China, Israel, Iran, Panama, Canada, Brazil, France, and Germany. Their ability of providing water vary from poor to great. Hence, we consider that our chosen countries are typical and representative, and our model is applicable for all the countries.

\section{DATA NORMALIZING}

We should normalize each indicator. There are positive indicators and negative indicators. The higher positive indicator, the better. The lower negative indicator, the better. Therefore, we use two methods to normalize such two kinds of indicators.

$x_{i}$ means different country's normalized data.

$\mathbf{X}=\left[x_{1}, x_{2}, \cdots, x_{n}\right]$ means The normalized data matrix

To positive indicator

$$
x_{i}=\left[\frac{x_{i}^{0}-\min \left(x_{1}^{0}, x_{2,}^{0} \cdots, x_{n}^{0}\right)}{\max \left(x_{1}^{0}, x^{0}, \cdots, x_{n}^{0}\right)-\min \left(x^{0}{ }_{1}, x^{0}{ }_{2}, \cdots, x_{n}{ }_{n}\right)}\right]
$$

To negative indicatax $\left(x_{i}^{0}{ }_{1}, x_{2,}^{0}=\left[\frac{\left.\cdots, x^{0}{ }_{n}\right)-x^{0}{ }_{i}}{\max \left(x^{0}{ }_{1}, x^{0}{ }_{2}, \cdots, x^{0}{ }_{n}\right)-\min \left(x_{1}^{0}, x_{2}^{0}, \cdots, x_{n}^{0}\right)}\right]\right.$

\section{THE MODEL OF PCA AND AHP}

\subsection{The model of PCA}

The second grade has several indicators, so we use PCA to reduce dimensions. More exactly, we can use less variables to represent the most change in the data. In the end, the model will give the weights of indicators in the second grade

Firstly, we use the normalized data and get the correlation coefficient matrix R.

Then, we calculate the eigenvalues $\lambda_{i}$ and the correspond eigenvectors $u_{i}$ of matrix R. So, we can use $u$ and $\mathrm{X}$ matrix to calculate principal component $y_{i}$.

When select $p$ principal components, we calculate the contribution rate of each principal component.

$b_{j}=\frac{\lambda_{j}}{\sum_{k=1}^{n} \lambda_{k}}(j=1,2, \cdots, n)$

If the sum of bj is greater than 0.85 , we can replace the $\mathrm{n}$ indicators with $\mathrm{p}$ principal component

At lase we can calculate the comprehensive evaluation value by following equation

$$
Z=\sum_{j=1}^{p} b_{j} y_{j}
$$

Where $b_{j}$ is the contribution rate of each principal component $j$.

\subsection{The model AHP}

We try to obtain the weight of indicators in the first grade. Because subjective judgment is illconsidered, we choose the Analytic Hierarchy Process (AHP), which can help give all the factors a sequence in the evaluation, according to the degree of importance.

Based on the data we have disposed, we get weights of supply indicators and weights of demand indicators. $\mathrm{W}_{1}$ stands for the weights of supply indicators. $W_{2}$ stands for the weights of demand indicators. What is worth mentioning, only when the model passes the test consistency, vectors of the maximum eigenvalue can be used as the weights of the indicators.

$$
\mathbf{W}_{1}=\left[w_{1}, w_{2}, w_{3}, w_{4}\right]=[0.73,0.17,0.07,0.03]
$$


$\mathbf{W}_{2}=\left[w_{1}, w_{2}, w_{3}\right]=[0.69,0.09,0.22]$

At last, the result pass the check consistency, so we can accept it.

\subsection{The Supply-and-Demand-Matching Model}

The score of Supply Ability and Demand Level is given by the model above.

$$
\begin{aligned}
& S A=\mathrm{W}_{1} \mathrm{X} \\
& D L=\mathrm{W}_{2} \mathrm{X}
\end{aligned}
$$

The Matching Degree of the Demand and Supply (MD) is defined as:

$$
M D=1-\frac{S}{F}
$$

Where $F=0.5(S A+D L)$

and $S=\sqrt{0.5\left[(S A-F)^{2}+(D L-F)^{2}\right]}$

The meaning of SA, DL and MD is worth to mention. The water supply ability could be directly reflected from SA. MD is a relatively objective and comprehensive evaluation of demand level. It is easily to compare a specific country to another, in order to know the relative level in the whole world.

Meanwhile, to the country itself, the adaptation between the supply ability and demand level is more vital. A single supply ability, whose value is big, doesn't mean the water is enough for every person. A single demand level, whose value is small, is the same. MD display the relationship between supply and demand. Thus, the water ability of the region can be shown more objective and credible through the measurement of Matching Degree.

\section{THE RESULTS}

Using the model we establish, we get the results of the ten countries shown in the Table 3 .

Table 3 Results

\begin{tabular}{|l|l|l|l|}
\hline Country & $\begin{array}{l}\text { Supply Abil- } \\
\text { ity }\end{array}$ & $\begin{array}{l}\text { Demand Lev- } \\
\text { el }\end{array}$ & $\begin{array}{l}\text { Matching De- } \\
\text { gree }\end{array}$ \\
\hline Brazil & 0.554 & 0.470 & 0.885 \\
\hline Germany & 0.185 & 0.281 & 0.707 \\
\hline France & 0.208 & 0.345 & 0.648 \\
\hline Canada & 0.925 & 0.504 & 0.583 \\
\hline Panama & 0.460 & 0.251 & 0.583 \\
\hline Libya & 0.236 & 0.512 & 0.477 \\
\hline China & 0.155 & 0.356 & 0.444 \\
\hline Israel & 0.174 & 0.417 & 0.419 \\
\hline Iran & 0.190 & 0.499 & 0.366 \\
\hline Congo & 0.712 & 0.224 & 0.262 \\
\hline
\end{tabular}

Comparing the value of SA and DL, we can find that Congo, Panama, Canada and Brazil can meet the basic needs of its population, together with some surplus. France and Germany can basically meet people's need, which stand for the average level. However, Libya, China, Israel and Iran have poor ability to provide clean water. The information on the website says that countries like Congo are mainly for large rivers in their region, countries like Libya are mainly for their dry climate, especially China for its large population. All the above verify the justifiable of our results. Our model is reasonable.

\section{THE CONCLUSION}

The adaptation between the supply ability and demand level is quite vital. Based on our knowledge and the reference from website, the level of matching degree is shown in Table 4.

Table 4 Matching Degree Level

\begin{tabular}{ll}
\hline Scale & Level \\
\hline $0-0.5$ & Poor \\
$0.5-0.7$ & Average \\
$0.7-1.0$ & Great \\
\hline
\end{tabular}

We can easily find Brazil and Germany have the best matching degree. For countries like Congo with much water surplus should pay careful attention to protect the cherish water resource, together with giving a hand to those countries with water scarcity. For countries like Libya and China, they should take action quickly to relieve the water problem.

Water resource is a matter of life and death. So long as we find a way to evaluate the ability of water sustainability, we should put more attention to the work, helping water resource poor countries to improve present situation. We still have a lot of work to do.

\section{REFERENCES}

[1] http://www.unep.org/dewa/vitalwater/article2.html

[2] http://www.fao.org/nr/water/aquastat/water_res/index.stm

[3] Mathematical modeling algorithms and application exercises Answers [M]. National Defense Industry Press, 2013.

[4] Shougui Si, Xi Sun. Mathematical modeling algorithm and application. Beijing: National Defence Industry Press, 2015.2.

[5] Qiyuan Jiang, Jinxing Xie. Mathematical model. Beijing: Higher Education Press, 2011. 